\title{
Effect of Cigarette Smoking on Semen Quality Parameters in Male Partners of Infertile Couple: A Cross Sectional Study
}

\author{
Shriniwas S Chitta ${ }^{1}$, Mohan K Tambe ${ }^{2}$, Piyush M Kherde ${ }^{3}$, Sumit S Aggarwal ${ }^{4}$, \\ Prerna D Nandedkar, Gajanan G Atram ${ }^{6}$ \\ ${ }^{1}$ Assistant Professor, Dept of Physiology, Govt Medical College, Akola \\ ${ }^{2}$ Associate Professor, Dept of Physiology, Govt Medical College, Nagpur \\ ${ }^{3}$ Assistant Professor, Dept of Physiology, Govt Medical College, Nagpur \\ ${ }^{4}$ Assistant Professor, Dept of Community Medicine, Govt Medical College, Akola \\ ${ }^{5}$ Assistant Professor, Dept of Biochemistry, Govt Medical College, Akola \\ ${ }^{5}$ Professor, Dept of Physiology, Govt Medical College, Akola
}

\begin{abstract}
Background: Cigarette smoking is a widely recognized health hazard, yet despite worldwide antismoking campaigns, some people continue to consume cigarettes on a regular basis. Likewise prevalence of infertility is also in increasing trend, and among the various cause cigarette smoking in one of the important cause for male infertility. So the present study was conducted objectives of, to assess how much is the impact of the various level of smoking on semen quality parameters in infertile males.

Methodology: Infertile males were selected in two groups smokers and Non-smokers which was referred from infertility clinic of Govt Medical college, Nagpur to dept of physiology for their semen analysis.

Results: There was statistically significant difference was observed between various level of smoking and Nonsmokers for the sperm count, motility and morphology.

Conclusion: the present study shows that smoking adversely affects the quality of semen, seminal parameters like sperm count, motility and morphology affected mostly; which are responsible for the normal fertility.
\end{abstract}

\section{Introduction}

Cigarette smoking is a widely recognized health hazard, yet despite worldwide antismoking campaigns, some people continue to consume cigarettes on a regular basis. In male dominated society; the curse of infertility is usually put on females though in most cases there is some contribution to the infertility from male counterpart. Soares SR et al $(2008)^{[1]}$, reviewing the literature concerning the relationship between cigarette smoking and reproductive function, highlighted a strong evidence indicating the negative effect of cigarette smoking on male and female fertility. A consistent number of studies have claimed that cigarette smoking is correlated with alterations in sperm quality such as semen volume, sperm concentration, motility, and morphology. ${ }^{[2,3]}$

It has been suggested that cigarette smoking increases the percentage of morphologically altered spermatozoa especially in men who are heavy smokers or who have smoked for many years. ${ }^{[4]}$ Cigarette smoke is heterogeneous aerosol produced due to incomplete combustion of tobacco leaf. It contains about 4000 pharmacologically active chemicals, which have antigenic, cytotoxic, mutagenic and carcinogenic properties. ${ }^{\text {[5] }}$

The different chemicals and their metabolites present in the smoke affect many seminal parameters viz. sperm count, motility, morphology and functions of spermatozoal organelle ultimately affecting the fertility status of the males ${ }^{[6]}$. Active transfer of several components of cigarette smoke through the blood-testis barrier may induce degradation of sperm parameters and nuclear quality of spermatozoa. Oxidative stress-induced DNA damage seems to be one of the major causes of sperm quality alteration ${ }^{[7]}$.

In the present study the conventional seminal parameters like sperm count, motility and morphology observed by routine semen analysis in different categories of smokers like mild smokers, moderate smokers and heavy smokers and non smoker infertile men.

\section{Material And Method}

The study has been conducted in the semen analysis laboratory in department of Physiology, Government Medical College \& Hospital, Nagpur from March 2011 to September 2012. Both the cases and controls were the male partners of the couples of primary infertility. For the study purpose primary infertility was defined as "couples who could not conceive after one year of their marriage \& who were not using any form of family planning methods was consider infertile". These infertile patients were referred from sex and 
marriage counselling clinic, Obstetrics and Gynaecology, after completion of their routine, haematological and urinary investigations.

It was a primary requirement to lay down stringent patient-selection criteria in order to exclude as many co-existing factors as possible, as they may otherwise influence or modify the effect of cigarette smoking on semen parameters. For the same reasons, we have selected infertile Non Smokers and Smokers, to exclude any undiscovered confounding factors present in infertile men, which might not be present in healthy fertile controls.

100 Infertile male of age 20-45 years having history of and cigarette smoking of more than one year were included as cases where as 100 infertile male who never smoked in their lifetime, were included as controls in the non-smoker group. They were further divided into three groups based on smoking severity found by asking history of number of cigarettes smoked per day. Mild smokers: 1-10 cigarettes/ day, Moderate smokers: 10-20 cigarettes/ day And Heavy smokers: > 20 cigarettes/ day. Patients suffering from secondary infertility, Persons with occupation near hot furnace and workers of chemical industries, Persons with history of infections, drug addiction and previous history of operation on genitourinary track were excluded. Institutional ethical clearance was obtained and informed written consent was taken from the subjects after explaining the study design.

Sample is collected in clean, sterile, warm and dry non spermicidal prelabelled $50 \mathrm{ml}$ container. Samples were obtained by masturbation. The samples were allowed to liquefy at least for 30 minutes protecting it from extremes of temperature i.e. below 20 and above 37 degree celcius. The routine semen analysis of Volume Of ejaculate, Sperm count/ml, Motile Sperm count/ml, Percentage Of motile Sperms, Morphologically Normal sperms was carried out after liquefaction, as per the guidelines laid down by W.H.O. ${ }^{8}$ Mean and standard deviation was calculated for each group by Microsoft Excel ${ }^{\circledR}$ Software. After collection of data, appropriate test were applied.

\section{Results}

Table 1 showing subgroups of smokers

\begin{tabular}{|l|l|l|}
\hline $\begin{array}{l}\text { Subgroups } \\
\text { of smokers }\end{array}$ & $\begin{array}{l}\text { Number of cigarettes } \\
\text { smoked per day }\end{array}$ & $\begin{array}{l}\text { No. of } \\
\text { Subjects }\end{array}$ \\
\hline Mild & $1-10$ cigarettes/ day & 35 \\
\hline Moderate & $10-20$ cigarettes/ day & 34 \\
\hline Heavy & $>20$ cigarettes/ day & 31 \\
\hline Total smokers & 100 \\
\hline
\end{tabular}

In the present study 100 infertile non-smokers were compared with 100 smokers. From above table 1 , out of 100 male, infertile smokers cases 35 were mild smokers, 34 were moderate smokers and 31 were severe smokers.

Table 2: Distribution of smokers and non smokers according to various semen quality parameters

\begin{tabular}{|c|c|c|c|c|c|c|}
\hline \multirow{2}{*}{$\begin{array}{c}\text { Seminal } \\
\text { Para- } \\
\text { Meters }\end{array}$} & \multirow{2}{*}{$\begin{array}{l}\text { Non-smokers } \\
(\mathrm{n}=100) \\
(\text { Mean } \pm \text { S.D. })\end{array}$} & \multicolumn{3}{|c|}{$\begin{array}{ll}\text { Smokers }(\mathrm{n}=100) & (\text { Mean } \pm \text { S.D. })\end{array}$} & \multirow{2}{*}{$\begin{array}{c}\mathrm{P} \\
\text { Value }\end{array}$} & \multirow{2}{*}{$\begin{array}{c}\text { Significance } \\
\text { Status }\end{array}$} \\
\hline & & $\begin{array}{c}\text { Mild } \\
(\mathrm{n}=35)\end{array}$ & Moderate $(\mathrm{n}=34)$ & $\begin{array}{l}\text { Heavy } \\
(\mathrm{n}=31)\end{array}$ & & \\
\hline Vol. (ml) & $3.3 \pm 1.01$ & $3.3 \pm 0.9$ & $3.1 \pm 0.6$ & $3.1 \pm 0.5$ & 0.258 & $\begin{array}{c}\text { Not } \\
\text { Significant }\end{array}$ \\
\hline $\begin{array}{c}\text { S.C./ml } \\
\text { (millions) }\end{array}$ & $71.3 \pm 24.2$ & $\begin{array}{r}70.2 \\
+12.5 \\
\end{array}$ & $66.2 \pm 15.8$ & $59.2 \pm 17.8$ & 0.032 & $\begin{array}{c}\text { Not } \\
\text { Significant } \\
\end{array}$ \\
\hline $\begin{array}{l}\text { M.S.C./ml } \\
\text { (millions) }\end{array}$ & $38.5 \pm 16.8$ & $\begin{array}{r}33.9 \\
+11.2 \\
\end{array}$ & $30.7 \pm 12$ & $26.5 \pm 11.2$ & 0.003 & $\begin{array}{c}\text { Not } \\
\text { Significant }\end{array}$ \\
\hline$\%$ Of M.S. & $54.2 \pm 15.8$ & $\begin{array}{l}48.3 \pm \\
12.7 \\
\end{array}$ & $46.3 \pm 13.7$ & $45.9 \pm 14.3$ & 0.006 & Significant \\
\hline M.N.S.(\%) & $26.4 \pm 12$ & $25.2 \pm 5.3$ & $26.3 \pm 9.3$ & $17.7 \pm 7$ & 0.004 & $\begin{array}{c}\text { Not } \\
\text { Significant }\end{array}$ \\
\hline
\end{tabular}

(Vol=Volume Of ejaculate, $\mathrm{SC}=$ Sperm count $/ \mathrm{ml}, \mathrm{MSC}=$ Motile Sperm count $/ \mathrm{ml}, \% \mathrm{MS}=$ Percentage Of motile Sperms, MNS=Morphologically Normal sperms)

From the above table Mean Volume of ejaculate $(\mathrm{ml})$ of non-smokers found to be $3.3 \pm 1.01 \mathrm{ml}$ while that of mild, moderate and heavy smokers was found to be $3.3 \pm 0.9,3.1 \pm 0.6$ and $3.1 \pm 0.5 \mathrm{ml}$ respectively. Relation between different level of smoking and semen volume was found to be not significant $(\mathrm{P}=0.258)$. Mean Sperm count $/ \mathrm{ml}$ (millions) of non-smokers was found to be $71.3 \pm 24.2$ millions while that of mild, moderate and heavy smokers was found to be $70.2 \pm 12.5,66.2 \pm 15.8$ and $59.2 \pm 17.8$ millions respectively. Relation between different level of smoking and Mean Sperm count/ml (millions) was found to be significant $(\mathrm{P}=0.032)$. Mean Motile Sperm count/ml (millions) of non-smokers was found to be $38.5 \pm 16.8$ millions while that of mild, moderate and heavy smokers was found to be $33.9 \pm 11.2,30.7 \pm 12$ and $26.5 \pm 11.2$ millions respectively. Relation between different level of smoking and Mean Motile Sperm count/ml (millions) was 
found to be significant $(\mathrm{P}=0.003)$. Mean Percentage of Motile Sperms of non-smokers was found to be 54.2 $\pm 15.8 \%$ while that of mild, moderate and heavy smokers was found to be $48.3 \pm 12.7,46.3 \pm 13.7$ and $45.9 \pm$ $14.3 \%$ respectively. Relation between different level of smoking and Mean Percentage of Motile Sperms was found to be significant $(\mathrm{P}=0.006)$. Mean of Morphologically Normal sperms $(\%)$ in non-smokers was found to be $26.4 \pm 12 \%$ while that of mild, moderate and heavy smokers was found to be $25.2 \pm 5.3,26.3 \pm 9.3$ and $17.7 \pm$ $7 \%$ respectively. Relation between Mean of Morphologically Normal sperms and smoking was found statistically significant $(\mathrm{P}<0.05)$.

Table 3: Comparison of seminal parameters in nonsmoker and mild smoker group

\begin{tabular}{|l|l|l|l|l|l|}
\hline $\begin{array}{l}\text { Sr. } \\
\text { No. }\end{array}$ & Parameters Group & $\begin{array}{l}\text { Nonsmokers } \\
(\mathbf{n = 1 0 0 )} \\
(\text { Mean } \pm \text { S.D. })\end{array}$ & $\begin{array}{l}\text { Mild } \\
(\mathbf{n = 3 5}) \\
(\text { Mean } \pm \text { S.D. })\end{array}$ & $\begin{array}{l}\text { t-Test } \\
\text { P value }\end{array}$ & Significance Status \\
\hline 1 & Vol. $(\mathrm{ml})$ & $3.3 \pm 1.01$ & $3.3 \pm 0.9$ & 0.893 & Not Significant \\
\hline 2 & S.C./ml (millions) & $71.3 \pm 24.2$ & $70.2 \pm 12.5$ & 0.792 & Not Significant \\
\hline 3 & M.S.C./ml (millions) & $38.5 \pm 16.8$ & $33.9 \pm 11.2$ & 0.138 & Not Significant \\
\hline 4 & \% Of M.S. & $54.2 \pm 15.8$ & $48.3 \pm 12.7$ & $\mathbf{0 . 0 4 9} *$ & Significant \\
\hline 5 & (\%) M.N.S. & $26.4 \pm 12$ & $25.2 \pm 5.3$ & 0.575 & Not Significant \\
\hline
\end{tabular}

(Vol=Volume Of ejaculate, $\mathrm{SC}=$ Sperm count $/ \mathrm{ml}, \mathrm{MSC}=$ Motile Sperm count $/ \mathrm{ml}, \% \mathrm{MS}=$ Percentage Of motile Sperms, MNS=Morphologically Normal sperms)

Above table shows that seminal parameters were compared between non-smokers and mild smokers, we found that the difference in the parameters was not statistically significant except for percentage of motile sperms which is statistically significant. ( $\mathrm{P}$ value $<0.05$ )

Table 4: Comparison of seminal parameters in nonsmoker and moderate smoker group

\begin{tabular}{|l|l|l|l|l|l|}
\hline S.N. & Group & $\begin{array}{l}\text { Nonsmokers } \\
(\mathbf{n = 1 0 0 )} \\
(\text { Mean } \pm \text { S.D. })\end{array}$ & $\begin{array}{l}\text { Moderate } \\
(\mathbf{n = 3 4 )} \\
(\mathbf{M e a n} \pm \text { S.D. })\end{array}$ & $\begin{array}{l}\text { t-Test } \\
\text { P value }\end{array}$ & Significance Status \\
\hline 1 & Vol. (ml) & $3.3 \pm 1.01$ & $3.1 \pm 0.6$ & 0.109 & Not Significant \\
\hline 2 & S.C./ml (millions) & $71.3 \pm 24.2$ & $66.2 \pm 15.8$ & 0.294 & Not Significant \\
\hline 3 & M.S.C./ml (millions) & $38.5 \pm 16.8$ & $30.7 \pm 12$ & 0.014 & Significant \\
\hline 4 & \% Of M.S. & $54.2 \pm 15.8$ & $46.3 \pm 13.7$ & 0.011 & Significant \\
\hline 5 & (\%) M.N.S. & $26.4 \pm 12$ & $26.3 \pm 9.3$ & 0.969 & Not Significant \\
\hline
\end{tabular}

(Vol=Volume Of ejaculate, $\mathrm{SC}=$ Sperm count $/ \mathrm{ml}, \mathrm{MSC}=$ Motile Sperm count $/ \mathrm{ml}, \% \mathrm{MS}=$ Percentage Of motile Sperms, MNS=Morphologically Normal sperms)

It was observed from above table that seminal parameters were compared between non-smokers and moderate smokers we found that the difference in the parameters was not statistically significant except for Motile Sperm count/ $\mathrm{ml}$ and percentage of motile sperms different of which is statistically significant. (P value $<0.05)$

Table 5: Comparison of seminal parameters in nonsmoker and heavy smoker group.

\begin{tabular}{|l|l|l|l|l|l|}
\hline S.N. & Group & $\begin{array}{l}\text { Nonsmokers } \\
(\mathbf{n = 1 0 0 )} \\
(\text { Mean } \pm \text { S.D. })\end{array}$ & $\begin{array}{l}\text { Heavy } \\
(\mathbf{n = 3 1 )} \\
(\mathbf{M e a n} \pm \text { S.D. })\end{array}$ & $\begin{array}{l}\text {-Test } \\
\mathbf{P} \\
\text { value }\end{array}$ & $\begin{array}{l}\text { Significance } \\
\text { Status }\end{array}$ \\
\hline 1 & Vol. (ml) & $3.3 \pm 1.01$ & $3.1 \pm 0.5$ & 0.213 & Not Significant \\
\hline 2 & S.C./ml (millions) & $71.3 \pm 24.2$ & $59.2 \pm 17.8$ & 0.011 & Significant \\
\hline 3 & M.S.C./ml (millions) & $38.5 \pm 16.8$ & $26.5 \pm 11.2$ & 0.003 & Significant \\
\hline 4 & \% Of M.S. & $54.2 \pm 15.8$ & $45.9 \pm 14.3$ & 0.010 & Significant \\
\hline 5 & (\%) M.N.S. & $26.4 \pm 12$ & $17.7 \pm 7$ & 0.0002 & $\begin{array}{l}\text { Highly } \\
\text { Significant }\end{array}$ \\
\hline
\end{tabular}

(Vol=Volume Of ejaculate, $\mathrm{SC}=$ Sperm count $/ \mathrm{ml}, \mathrm{MSC}=$ Motile Sperm count $/ \mathrm{ml}, \% \mathrm{MS}=$ Percentage Of motile Sperms, MNS=Morphologically Normal sperms)

Table 5 shown that when seminal parameters were compared between non-smokers and heavy smokers we found that the difference in all the parameters was statistically significant except for Volume of ejaculate $(\mathrm{ml})$ which is statistically not significant $(\mathrm{P}$ value $>0.05)$. Statistically highly significant difference is found in morphology of the two groups. ( $\mathrm{P}$ value $<0.001)$

\section{Discussion}


In the present study 100 patients were selected in both group i.e. Non smoker and Smokers to neutralised other confounding factors which can effect seminal quality parameter. Findings was almost similier to present study related to mean volume of ejaculate (ml, which was conducted by Wang S.L. et. al. (2001) ${ }^{[9]}$, study shows that heavy smoking causes significant decrease in sperm count. Findings of present study are consistent with Aryanpur et al (2011) ${ }^{[10]}$ Cigarette smoke is directly or indirectly toxic to spermatogenesis. Literature review show that Nicotine the main alkaloid of tobacco is known to elevate the plasma epinephrine and this elevation stimulates the secretion of ACTH. The adrenal cortical hyperactivity, resulting in induced stress, causes high level of catecholamines in the body, which is a known vasoconstrictor. Because of vasoconstriction as well as due to action of nicotine there occurs impairment of Leydig cell function ${ }^{[11]}$. These alterations in steroidogenesis ultimately lead to decreased testosterone levels, which in turn causes disturbances in spermatogenesis leading to decrease in sperm count ${ }^{[12]}$. Smoking by increasing blood catecholamine levels then may increase the conversion of testosterone to estradiol via aromatization, thereby increasing the level of serum oestradiol. Oestradiol might impair spermatogenesis by several mechanisms. It inhibits the biosynthesis of testicular testosterone. It may also achieve a negative effect upon sperm count by enhancing catecholamine activity. The high concentration of catecholamines may cause ischemia in seminiferous tubules causing impaired spermatogenesis, ultimately affecting sperm count ${ }^{[13]}$.

Our study results of mean motile sperms are consistent with several researchers like, Banerjee A et al (1993) ${ }^{[14]}$ who showed, percentage of motile sperm and total sperm count were significantly lower $(\mathrm{p}<.05)$. MF et al. (1996) ${ }^{[15]}$, Gaur D.S. et al (2007) ${ }^{[4]}$ Showed Peroxidative damage to the sperm membrane and axonemal proteins appears to be the cause of permanent impairment in sperm motility. Besides carbon monoxide and hydrocyanic acid $(\mathrm{HCN})$ other factors that are potentially highly toxic exist among the 4000 components identified in cigarette smoke, and produce the detrimental effects on spermatozoa. The cilliary toxins in cigarette smoke might affect the sperm tail movement, as cilia and sperm tail have much common anatomically concerning their tubular architecture and their mode of action. Compounds inhaled in smoke might reach spermatozoa via the blood stream crossing blood- testis barrier either in the original form or a modified metabolic products. The blood testis barrier is not an absolute barrier, it is able to protect the mature sperm or their precursors only to certain extent; and still allows the entry of many compounds into seminiferous tubules [6].

Smoking large quantity of cigarettes affects the ultra structure of the flagellum and more specifically the axoneme of human spermatozoa, which is so important for the motility of sperm. The ultra structural assessment of axoneme showed that severe ultra structural abnormalities were present in $99 \%$ of smokers as compared to $26 \%$ of non-smokers ${ }^{[3]}$. This might be one of the causes of decreased sperm motility among heavy smokers.

The presence of asthenozoospermia can be a very subtle "early indicator" of reduction in the semen quality of an individual, which frequently is ignored, if the semen sample shows adequate sperm count and normal morphology ${ }^{[13]}$.

Gaur D.S. et al (2007) ${ }^{[4]}$ showed similar correlation regarding sperm morphology with present study. However researchers like Wang S.L.et al (2001) ${ }^{[9]}$, did not find any significant difference in the morphology between smokers and non-smokers.

The mechanism behind the harmful effect of smoking on semen quality is not fully understood. Direct exposure of spermatozoa to the toxins in cigarettes smoke probably tilts the delicate balance of reactive oxygen species (ROS) that are produced by spermatozoa for their special functions like decapitation. Increased quantities of ROS have been shown to be detrimental to the DNA of spermatozoa. Thus producing a negative effect on the viability and morphology of spermatozoa ${ }^{[17]}$. Oxidants in cigarette smoke are thought to damage sperm DNA, and smokers have more oxidative DNA damage in their sperm than do non-smokers ${ }^{18}$. An adverse effect of reactive oxygen species (ROS) on sperm quality is a possibility that could justify the observed sperm damage, since elevated levels of ROS have been found in infertile smoking men ${ }^{[19]}$.

\section{Conclusion}

So smoking adversely affects the quality of semen, seminal parameters like sperm count, motility and morphology affected mostly; which are responsible for the normal fertility. There is dose dependant decrease in semen quality (motility \& morphology) where heavy smoker group is worst affected. Motility is the parameter, which gets affected early but further study is required for the confirmation of the statement.

\section{References}

[1]. Soares SR, Melo MA. Cigarette smoking and reproductive function.Curr Opin Obstet Gynecol. 2008;20:281-91.

[2]. Vine MF, Margolin BH, Morrison HI, Hulka BS. Cigarette smoking and sperm density: a meta-analysis. Fertil Steril. 1994;61:3543.

[3]. Zavos P, Correa J, Antypas S, Zarmakoupis-Zavos P, Costantinos N.Effects of seminal plasma from cigarette smokers on sperm viability and longevity. Fertil Steril. 1998a;69:425-429. 
[4]. Gaur DS, Talekar M, Pathak VP. Effect of cigarette smoking on semen quality of infertile men. Singap Med J. 2007;48:119-123.

[5]. Burns DM, Fauci et al editors.Nicotine addiction. Harrison's principle of internal medicine, $16^{\text {th }}$ ed. Newyork. Mc-Graw Hill Companies: p 2573-2575.

[6]. Makler A, Reiss J, Stoller $\mathbf{J}$ et al. Use of sealed minichamber for direct observationand and evaluation of the in vitro effect of cigarette smoke on sperm motility; Fertil Steril,1993;59(3);645-651

[7]. Guillet-May F, et al .Negative impact of cigarette smoking on male fertility: from spermatozoa to the offspring.J Gynecol Obstet Biol Reprod (Paris). 2004; 33(5): 384-390

[8]. WHO laboratory manual for Examination and processing of human semen. $5^{\text {th }}$ ed.2010. Geneva .WHO press.

[9]. Wang S-lin, Wang X-ru, Chia S-eng, Shen H-ming, Song L, Chen H-yan, et al. A Study on Occupational Exposure to Petrochemicals and Smoking on Seminal Quality. Journal of Andrology. 2001;22(1).

[10]. Aryanpur M, Tarahomi M, Sharifi H. Comparison of Spermatozoa Quality in Male Smokers and Nonsmokers of Iranian Infertile Couples. International Journal Of Fertility. 2011;5(3):152-7

[11]. Mattison DR. The effects of smoking on fertility from gametogenesis to implantation. Environ Res 1982,28:410-33

[12]. Shaarawy Mmahmoud KZ .Endocrine profile and semen characteristics in male smokers.Fertil Steril 1982,38:255-257

[13]. Klaiber EL, Broverman DM. Dynamics of estradiol and testosterone and seminal fluid indexes in smokers and nonsmokers. Fertil Steril 1988; 50 630-4

[14]. Banerjee A, Pakrashi A, Chatterjee S, Ghosh S, Dutta SK. Semen characteristics of tobacco users in India. Arch Androl 1993;30(1):35-40

[15]. Vine MF. Smoking and male reproduction: a review. Int J Androl.1996;19:323-337

[16]. Chohan KR, Badawy SZA. Cigarette Smoking Impairs Sperm Bioenergetics. International Braz J Urol. 2010;36(1):60-5

[17]. Koksal IT, Usta M, Orhan I, Abbasoglu S, Kadioglu A. Potential role of reactive oxygen species on testicular pathology associated with infertility. Asian J Androl 2003; 2:95-9

[18]. Horak S, Polanska J, Widlak P: Bulky DNA adducts in human sperm: relationship with fertility, semen quality, smoking, and environmental factors. Mutat Res. 2003; 537: 53-

[19]. Saleh RA, Agarwal A, Sharma RK, Nelson DR, Thomas AJ. Effect of cigarette smoking on levels of seminal oxidative stress in infertile men. A. Infertility. 2002;78(3) 